\title{
Voruciclib, a Potent CDK4/6 Inhibitor, Antagonizes ABCB1 and ABCG2-Mediated Multi-Drug Resistance in Cancer Cells
}

\author{
Pranav Gupta $^{a} \quad$ Yun-Kai Zhang ${ }^{a} \quad$ Xiao-Yu Zhang ${ }^{a} \quad$ Yi-Jun Wang ${ }^{a}$ Kimberly W. Lu ${ }^{a}$ \\ Timothy Hall ${ }^{a}$ Richard Peng ${ }^{a}$ Dong-Hua Yang ${ }^{a} \quad$ Ni Xie $^{b}$ Zhe-Sheng Chen ${ }^{a}$ \\ aDepartment of Pharmaceutical Sciences, College of Pharmacy and Health Sciences, St. John's \\ University, Queens, NY, USA; 'Institute of translation medicine, Shenzhen Second People's Hospital, \\ First Affiliated Hospital of Shenzhen University, Shenzhen, China
}

\section{Key Words}

Voruciclib - ATP-binding cassette transporters • ABCB1 • ABCG2 • Multidrug resistance

\begin{abstract}
Background/Aims: The overexpression of ATP-Binding Cassette (ABC) transporters has known to be one of the major obstacles impeding the success of chemotherapy in drug resistant cancers. In this study, we evaluated voruciclib, a CDK 4/6 inhibitor, for its chemo-sensitizing activity in ABCB1- and ABCG2- overexpressing cells. Methods: Cytotoxicity and reversal effect of voruciclib was determined by MTT assay. The intracellular accumulation and efflux of ABCB1 and $A B C G 2$ substrates were measured by scintillation counter. The effects on expression and intracellular localization of $A B C B 1$ and $A B C G 2$ proteins were determined by Western blotting and immunofluorescence, respectively. Vanadate-sensitive ATPase assay was done to determine the effect of voruciclib on the ATPase activity of ABCB1 and ABCG2. Flow cytometric analysis was done to determine the effect of voruciclib on apoptosis of ABCB1 and ABCG2overexpressing cells and docking analysis was done to determine the interaction of voruciclib with $A B C B 1$ and $A C B G 2$ protein. Results: Voruciclib significantly potentiated the effect of paclitaxel and doxorubicin in ABCB1-overexpressing cells, as well as mitoxantrone and SN-38 in ABCG2-overexpressing cells. Voruciclib moderately sensitized ABCC10- overexpressing cells to paclitaxel, whereas it did not alter the cytotoxicity of substrates of $A B C C 1$. Furthermore, voruciclib increased the intracellular accumulation and decreased the efflux of substrate anti-cancer drugs from ABCB1- or ABCG2-overexpressing cells. However, voruciclib did not alter the expression or the sub-cellular localization of $A B C B 1$ or $A B C G 2$. Voruciclib stimulated the ATPase activity of both $A B C B 1$ and $A B C G 2$ in a concentration-dependent manner. Lastly, voruciclib exhibited a drug-induced apoptotic effect in ABCB1- or ABCG2- overexpressing cells. Conclusion: Voruciclib is currently a phase I clinical trial drug. Our findings strongly support its potential use in combination with conventional anti-cancer drugs for cancer chemotherapy.

(C) 2018 The Author(s)

Published by S. Karger AG, Basel

Zhe-Sheng Chen

and $\mathrm{Ni} \mathrm{Xie}$




\section{Introduction}

Multidrug resistance (MDR), defined as the resistance to chemotherapeutic drugs that are not similar in their chemical structure and mechanism of action, hinders the success of chemotherapy $[1,2]$. Over the years, a number of intrinsic and extrinsic cellular mechanisms have been identified and reported to cause MDR in cancer cells, some of which include, alteration in cyclin-dependent kinases (CDKs), regulation of apoptosis, autophagy, and increased DNA repair mechanisms [3-6]. However, the ABC transporters-mediated efflux of chemotherapeutic drugs is the most prominent factor leading to the development of MDR $[7,8]$.

Located on the plasma membrane of cells, $\mathrm{ABC}$ transporter is a super family consisting of 49 members classified into seven subfamilies (A-G), out of which ABCB1, ABCG2 and ABCCs are well documented to induce MDR in cancer cells [5, 9]. ABCB1, also known as P-glycoprotein (P-gp), is ubiquitously expressed in kidney, intestine, brain, and placenta [2]. ABCB1 effluxes a number of chemotherapeutic drugs like paclitaxel, doxorubicin, and vincristine $[1,2,10]$. ABCG2, also known as breast cancer resistance protein (BCRP), is expressed on the apical surface of small intestines, liver canalicular membrane, colon epithelium, and in placental syncytiotrophoblasts $[9,11]$. Some common substrates of ABCG2 include mitoxantrone, SN-38, and topotecan $[12,13]$. Since, the efflux function of ABCB1 and ABCG2 prevents the normal cells from building up toxins; their actions are considered to be protective and homeostatic. Contrastingly, in cancer cells, the efflux function causes a decrease in intracellular concentration of the chemotherapeutic drugs and thus, the actions of $\mathrm{ABCB} 1$ and $\mathrm{ABCG} 2$ are deleterious.

Over the past three decades, a number of efflux function modulators have been developed and investigated for their inhibitory action against ABCB1 and ABCG2-mediated MDR [7, 1416]. Voruciclib, a CDK4/6 inhibitor, has shown promising anti-cancer effects in combination with the BRAF inhibitor, vemurafenib in advanced BRAF-mutant melanoma [17]. More recent studies have shown that voruciclib enhances the sensitivity of the proteasome inhibitor, bortezomib, in triple negative breast cancer xenografts [18]. However, there is no published data indicating the sensitizing effects of voruciclib in cells overexpressing $\mathrm{ABC}$ transporters. Here, for the first time, we report that voruciclib blocks the efflux function of ABCB1 and ABCG2 and sensitizes cancer cells to chemotherapeutic drugs.

\section{Materials and Methods}

\section{Reagents}

Voruciclib (Fig. 1A) was obtained from ChemieTek (Indianapolis, IN). Dulbecco's modified Eagle's Medium (DMEM), fetal bovine serum (FBS), penicillin/streptomycin and trypsin $0.25 \%$ were purchased from Hyclone (Pittsburgh, PA). Monoclonal antibody against ABCB1, ABCG2, and beta-actin were purchased from Thermo Fisher Scientific Inc. (Rockford, IL). Alexa Fluor 488 conjugated goat anti-mouse IgG secondary antibody and SN-38 were also purchased from Thermo Fisher Scientific Inc. (Rockford, IL). Paclitaxel, doxorubicin, vincristine, cisplatin, mitoxantrone, and verapamil were purchased from SigmaAldrich (St. Louis, MO). [ $\left.{ }^{3} \mathrm{H}\right]$-paclitaxel $(15 \mathrm{Ci} / \mathrm{mmol})$ and $\left[{ }^{3} \mathrm{H}\right]$-mitoxantrone $(2.5 \mathrm{Ci} / \mathrm{mmol})$ were purchased from Moravek Biochemicals, Inc (Brea, CA). Propidium iodide (PI) and Annexin-V were purchased from BD biosciences (San Jose, CA). The chemicals for the ATPase assay were similar to those used in our previous study [19]. Fumitremorgin C (FTC) was a gift from Dr. Susan Bates (Columbia University, NY).

\section{Cell lines and cell culture}

The human colorectal adenocarcinoma cell line SW620, its doxorubicin-selected SW620/AD300 cell line, the porcine kidney epithelial cell line LLC-PK1 and LLC-PK1/MDR1 (transfected with human ABCB1 cDNA [20]) were used for ABCB1 reversal study. The non-small cell lung cancer cell line NCI-H460, its mitoxantrone-selected NCI-H460/MX20, and HEK293 cells transfected with either empty pcDNA3.1 vector (HEK293/pcDNA3.1) or vector containing wild type ABCG2 (HEK/ABCG2-R482) or mutants of ABCG2 
Fig. 1. Chemical structure of voruciclib and cytotoxicity of voruciclib in parental and drug-resistant cells. (A) Chemical structure of voruciclib (2-(2-Chloro-4(trifluoromethyl) phenyl)-5, 7-dihydroxy-8-((2R, 3S)2-(hydroxymethyl)-1-methylpyrrolidin-3-yl)-4H-1benzopyran-4-one). Cell survival (\%) percentage was measured after treatment with voruciclib for $72 \mathrm{~h}$ in parental and drug-resistant cells: SW620 and SW620/ AD300 cells (B), NCI-H460 and NCI-H460/MX20 cells (C), LLC-PK1 and LLC-PK1/MDR1 (D) HEK293/pcDNA3.1 and HEK/ABCG2-R482, HEK/ABCG2-R482G, HEK/ABCG2R482T (E). Points with error bars represent the mean \pm SD for independent determinations in triplicate. The above Fig.s are representative of three independent experiments.

(HEK/ABCG2-R482G and HEK/ABCG2-R482T) were used for ABCG2 reversal study. HEK293/ABCC1 and HEK293/ ABCC10 cells were generated by transfecting the HEK293 cells with $\mathrm{ABCC} 1$ or $\mathrm{ABCC} 10$ expression vector, respectively [21]. The transfected cells were cultured in a medium containing $2 \mathrm{mg} / \mathrm{mL}$ of G418 and all other cell lines were cultured at $37^{\circ} \mathrm{C}, 5 \% \mathrm{CO}_{2}$ with DMEM containing $10 \%$ FBS and $1 \%$ penicillin/streptomycin.

\section{MTT assay}

The modified MTT colorimetric assay was used to detect the sensitivity of cells to anticancer drugs in vitro as previously described [19, 22]. The cells were trypsinized and resuspended in a final concentration of 4 $\times 10^{3}$ cells/well. The cells were seeded into 96 well plates and incubated for $24 \mathrm{~h}$. Subsequently, $20 \mu \mathrm{l}$ of voruciclib at the indicated concentrations $(0-100 \mu \mathrm{M})$ was added to determine its cytotoxicity. In order to investigate the reversal effects of voruciclib, different concentrations of chemotherapeutic drugs $(20 \mu \mathrm{l} /$ well $)$ were added after pre-incubation with voruciclib, verapamil, or FTC for $2 \mathrm{~h}$. After $72 \mathrm{~h}$ of incubation, MTT reagent $(4 \mathrm{mg} / \mathrm{ml}$ and $20 \mu \mathrm{l} /$ well) was added and the plates were further incubated for $4 \mathrm{~h}$. Subsequently, the MTT and medium was removed and $100 \mu \mathrm{l}$ DMSO was added to dissolve the formazan crystals formed by the viable cells. Absorbance was determined at $570 \mathrm{~nm}$ by Opsys microplate reader (Dynex Technologies, Chantilly, VA). The $\mathrm{IC}_{50}$ (concentration required to inhibit the growth by $50 \%$ ) values were calculated from the survival curves using modified Bliss method [23]. Resistance fold

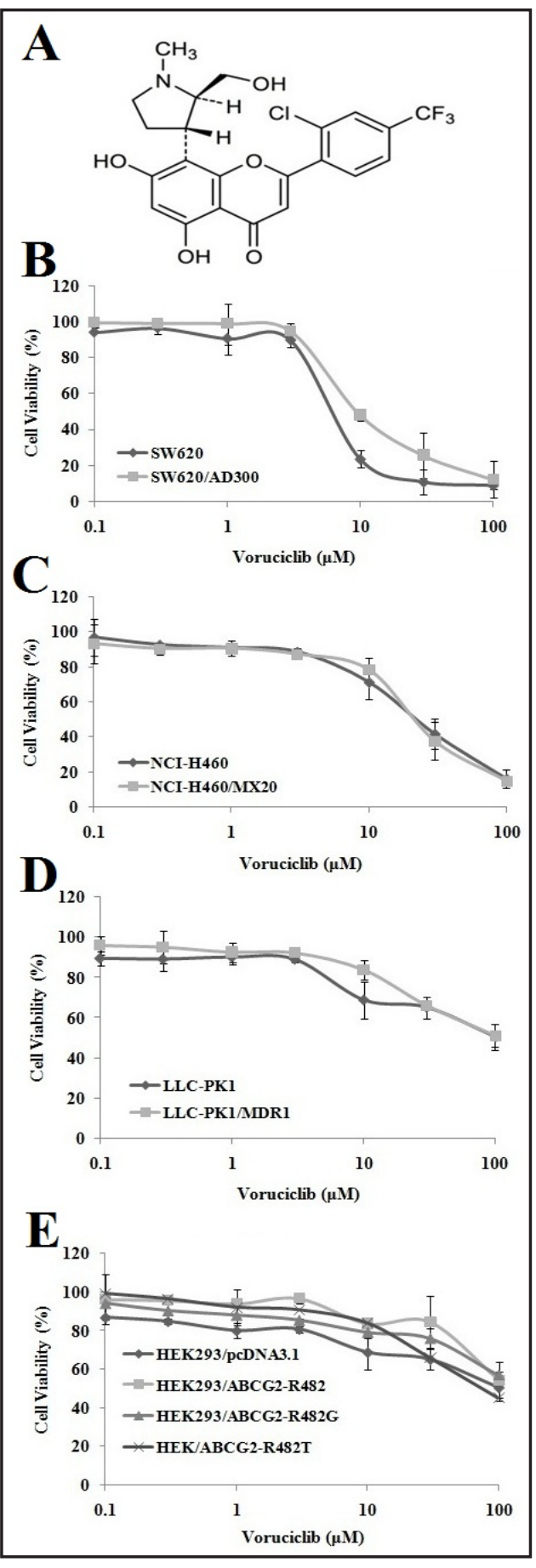
(Rf) was calculated by dividing the $\mathrm{IC}_{50}$ for the resistant cells with or without an inhibitor by that of the parental cells without an inhibitor. The concentrations of voruciclib as a potential reversal agent used in this study were $1 \mu \mathrm{M}$ and $5 \mu \mathrm{M}$. Verapamil $(5 \mu \mathrm{M})$ and FTC $(5 \mu \mathrm{M})$ were used as a positive control inhibitor of ABCB1 and ABCG2, respectively.

\section{Doxorubicin and mitoxantrone intracellular accumulation assay}

Cells grown on sterile coverslips were treated with or without $5 \mu \mathrm{M}$ voruciclib for $1 \mathrm{~h}$. Subsequently, the SW620 and SW620/AD300 cells were incubated with $5 \mu \mathrm{M}$ doxorubicin and the NCI-H460 and NCI-H460/ MX20 cells were incubated with $5 \mu \mathrm{M}$ mitoxantrone for $2 \mathrm{~h}$, followed by examination under the fluorescence microscope. 


\section{Cellular Physiology Cell Physiol Biochem 2018;45:1515-1528

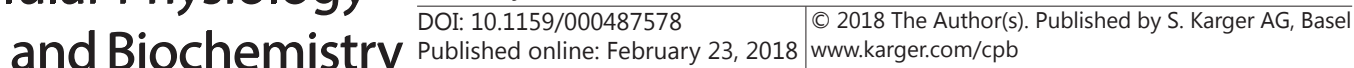

Gupta et al.: Voruciclib Reverses ABCB1 and ABCG2 Mediated MDR

\section{$\left.{ }^{\beta} \mathrm{H}\right]$-paclitaxel or $\left[{ }^{3} \mathrm{H}\right]$-mitoxantrone accumulation assay}

The SW620, SW620/AD300, NCI-H460, and NCI-H460/MX20 cells were pre-incubated with PBS, voruciclib $(1$ and $5 \mu \mathrm{M})$, verapamil $(5 \mu \mathrm{M})$ or FTC $(5 \mu \mathrm{M})$ for $1 \mathrm{~h}$. The cells were further incubated with either $0.1 \mu \mathrm{M}\left[{ }^{3} \mathrm{H}\right]$-paclitaxel or $0.1 \mu \mathrm{M}\left[{ }^{3} \mathrm{H}\right]$-mitoxantrone for $2 \mathrm{~h}$. Subsequently, the cells were washed with ice cold PBS and lysed by $10 \mathrm{mM}$ lysis buffer (pH 7.4, containing $1 \%$ Triton X-100 and $0.2 \%$ SDS). The lysed cells were placed in scintillation vials with $5 \mathrm{ml}$ scintillation fluid. Radioactivity was measured in the Packard TRI-CARB 1900CA liquid scintillation analyzer (Packard Instrument, Downers Grove, IL).

\section{[ $\left.{ }^{3} \mathrm{H}\right]$-paclitaxel or [ $\left.{ }^{3} \mathrm{H}\right]$-mitoxantrone efflux assay}

Following the accumulation assay, the cells were incubated in fresh DMEM media with or without reversal drugs and serial aliquots were taken at $0,30,60$, and $120 \mathrm{~min}$. The aliquots were analyzed for the efflux of $\left[{ }^{3} \mathrm{H}\right]$-paclitaxel or $\left[{ }^{3} \mathrm{H}\right]$-mitoxantrone as previously described [24].

\section{Preparation of total cell lysates}

The voruciclib treated and un-treated cells were harvested and lysed with lysis buffer for $30 \mathrm{~min}$ on ice, followed by centrifugation at $12,000 \mathrm{rpm}$ at $4^{\circ} \mathrm{C}$ for $20 \mathrm{~min}$. The supernatant was collected and protein concentration was determined by bicinchoninic acid $\left(\mathrm{BCA}^{\mathrm{TM}}\right)$-based protein assay (Thermo Scientific, Rockford, IL).

\section{Western blotting}

Equal amounts of total cell lysates (60 $\mu \mathrm{g}$ protein) were resolved by SDS-PAGE and transferred onto polyvinylidene fluoride membranes. The membranes were blocked with $5 \%$ skim milk dissolved in TBST buffer ( $10 \mathrm{mmol} \cdot \mathrm{L}^{-1}$ Tris-HCL, $150 \mathrm{mmol} \cdot \mathrm{L}^{-1} \mathrm{NaCl}$ and $0.1 \%$ Tween $20 \mathrm{pH} \mathrm{8.0)}$ to block nonspecific binding. The blot was probed with primary antibody C219 (ABCB1 specific; dilution 1:500), BXP-21 (ABCG2 specific; dilution 1:500), and 13E5 ( $\beta$-actin specific; dilution 1:1000), overnight at $4^{\circ} \mathrm{C}$, followed by incubation with HRP (horseradish peroxidase)-conjugated secondary antibody, on the next day. The enhanced chemiluminescence detection system was used to detect the protein-antibody complex. The expression of $\beta$-actin was used as a loading control and the protein expression was quantified by Image $1.47 \mathrm{v}$ Software (NIH, MD)

\section{Immunofluorescence}

The cells were treated with $5 \mu \mathrm{M}$ voruciclib for $24,48,72$, and $96 \mathrm{~h}$ and the fluorescent detection for $\mathrm{ABCB} 1$ and $\mathrm{ABCG} 2$ was performed as previously described [25, 26].

\section{ATPase assay}

The vanadate-sensitive ATPase activity of ABCB1 and ABCG2 in crude membranes of High-five insect cells was measured in the presence of voruciclib ( 0 to $40 \mu \mathrm{M}$ ) by PREDEASY ATPase Kits with modified protocols, as previously described [22, 27].

\section{Apoptosis analysis}

Voruciclib $(5 \mu \mathrm{M})$ alone or in combination with either paclitaxel or mitoxantrone was tested for its ability to induce apoptosis in parental and ABCB1- or ABCG2- overexpressing cells. Flow cytometric analysis was performed as previously described using FL-1 and FL-2 filters of a BD Accuri ${ }^{\text {TM }}$ C6 flow cytometer [28, 29].

\section{Induced-fit docking of Voruciclib into human homology ABCB1 and ABCG2}

Human homology ABCB1 model based on refined mouse ABCB1 (PDB ID: 4M1M) was provided by S. Aller and the docking grid was refined within the transmembrane region as previously described $[19$, 30]. Our previous grid on human homology ABCG2 on centroid of Arg482 was used for docking on ABCG2 [31]. The structure of voruciclib was built in Maestro and prepared by Ligprep 3.3. The energy minimized structure of voruciclib was then subjected to Glide v6.6 XP (extra precision) docking. In order to generate a closer conformation of ABCB1 or ABCG2 to the shape of voruciclib and to lead to better binding affinity complex, the IFD (induced-fit docking) protocol was carried out using Glide v6.6 (Schrödinger, USA, 2015) in this study. Generally, at the transmembrane domain of protein, the best scored voruciclib from XP run was used to generate the grid for IFD docking calculation. The default Glide IFD protocol was followed and the docking score (kcal/mol) was calculated. Top scoring docked complexes of ABCB1-voruciclib and ABCG2- 
voruciclib were used to interaction analysis and graphic representation. All computations were carried out on a 6-core Intel Xeon Processor with a Mac OS.

\section{Statistical analysis}

All experiments were repeated at least three times and the differences were determined using the two-tailed student's t-test (Microsoft Excel 2010) and statistical significance was determined at $\mathrm{p}<0.05$.

\section{Results}

Cytotoxic effects of voruciclib on parental and ABCB1-or ABCG2-overexpressing cells

Prior to investigating the reversal effects of voruciclib, its cytotoxicity was evaluated using the MTT assay. As shown in Fig. 1, more than 85\% of both parental and ABCB1- or ABCG2- overexpressing cells survived at the concentration of $5 \mu \mathrm{M}$ voruciclib, indicating that voruciclib is safe to be used up to a concentration of $5 \mu \mathrm{M}$. Thus, voruciclib at 1 and $5 \mu \mathrm{M}$ was tested in combination with chemotherapeutic drugs for its ability to reverse ABCB1 and ABCG2-mediated MDR.

\section{Effect of voruciclib on $A B C B 1$ substrates in cell lines overexpressing ABCB1}

The effect of voruciclib on ABCB1 substrates was determined by conducting cell survival assays. Paclitaxel and doxorubicin exhibited much higher $\mathrm{IC}_{50}$ to $\mathrm{ABCB} 1$-overexpressing SW620/AD300 cells than the parental SW620 cells. Voruciclib at 1 and $5 \mu \mathrm{M}$ significantly sensitized SW620/AD300 cells to the substrates of ABCB1, as shown in Table 1. Similar reduction in $\mathrm{IC}_{50}$ values of paclitaxel and doxorubicin was observed in transfected LLC-PK1/ MDR1 cells on exposure to 1 or $5 \mu \mathrm{M}$ voruciclib. Verapamil at $5 \mu \mathrm{M}$ was used a positive control inhibitor while cisplatin, a non-ABCB1 substrate, was used a negative control.

\section{Effect of voruciclib on ABCG2 substrates in cell lines overexpressing wild-type and mutant} ABCG2

Since polymorphism in ABCG2 is known to alter substrate and antagonist specificity [14], the effects of voruciclib were determined in both wild-type (R482) and mutant (R482G and R482T) ABCG2. As shown in Table 2, voruciclib at 1 and $5 \mu \mathrm{M}$, produced a concentration-dependent decrease in ABCG2mediated resistance to mitoxantrone and SN38 as indicated by the decrease in the $\mathrm{IC}_{50}$ values in $\mathrm{HEK} /$ ABCG2-R482, HEK/ ABCG2-R482G and HEK/ABCG2-R482T cells. In addition, voruciclib showed similar effect in ABCG2-overexpressing N C I-H 460 / M X 20 cells (Table 3). Meanwhile, treatment with voruciclib did not significantly change the $\mathrm{IC}_{50}$ value of mitoxantrone and $\mathrm{SN}-38$ in parental

Table 1. The effect of Voruciclib on reversal of ABCB1-mediated MDR. a $\mathrm{IC}_{50}$ values are represented as mean \pm SD of at least three independent experiments $(n=3)$ performed in triplicate. ${ }^{b}$ FR: Resistance fold was calculated by dividing the $\mathrm{IC}_{50}$ values of substrates in the presence or absence of inhibitor by the $\mathrm{IC}_{50}$ of parental cells without inhibitor. ${ }^{\mathrm{c}} \mathrm{P}<0.05$ versus the control group without reversal agent

\begin{tabular}{|c|c|c|c|c|}
\hline Treatment & $\begin{array}{c}\text { SW620 } \\
\left(\mu \mathrm{M}, \mathrm{FR}^{\mathrm{b}}\right)\end{array}$ & $\begin{array}{c}\text { SW620/AD300 } \\
\left(\mu M^{2}, F^{b}\right)\end{array}$ & $\begin{array}{c}\mathrm{IC}_{50} \pm \mathrm{SD}^{\mathrm{a}} \\
\mathrm{LLC}-\mathrm{PK} 1 \\
\left(\mathrm{nM}, \mathrm{FR} \mathrm{b}^{\mathrm{b}}\right)\end{array}$ & $\begin{array}{c}\text { LLC-PK1/MDR1 } \\
\text { (nM, FR') }\end{array}$ \\
\hline Paclitaxel & $\begin{array}{c}0.06+0.01 \\
\text { (1) }\end{array}$ & & & \\
\hline$+1 \mu \mathrm{M}$ & $0.08+0.01$ & $17.06+2.86(284.3)$ & $90.10+8.31(1)$ & $2720+118.67(30.2)$ \\
\hline Voruciclib & (1.3) & $3.62+0.91(45.2)^{c}$ & $90.32+7.63(1.02)$ & $1320.98+98.87(14.6)^{c}$ \\
\hline & $0.07+0.03$ & $0.97+0.09(16.1)^{c}$ & $90.54+9.83(1.04)$ & $110.78+6.58(1.2)^{c}$ \\
\hline $\begin{array}{l}\text { Voruciclib } \\
+5 \text { M }\end{array}$ & $(1.1)$ & $1.04+0.12(17.3)^{c}$ & $86.96+8.26(0.9)$ & $90.40+7.18(1)^{c}$ \\
\hline $\begin{array}{l}+5 \mu \mathrm{M} \\
\text { Verapamil }\end{array}$ & $\begin{array}{c}0.06+0.01 \\
\text { (1) }\end{array}$ & & & \\
\hline Doxorubicin & $\begin{array}{c}0.19+0.04 \\
\text { (1) }\end{array}$ & & & \\
\hline$+1 \mu \mathrm{M}$ & $0.12+0.06$ & $130.92+14.68(689.1)$ & $116.76+11.56(1)$ & $6300.14+189.87(53.9)$ \\
\hline Voruciclib & $(0.6)$ & $14.67+2.01(77.2)^{\mathrm{c}}$ & $98.23+8.65(0.8)$ & $1060.84+103.34(9.0)^{c}$ \\
\hline $\begin{array}{l}+5 \mu \mathrm{M} \\
+ \text { Voruciclib }\end{array}$ & $0.12+0.04$ & $2.58+0.95(13.5)^{c}$ & $80.49+6.38(0.7)$ & $150.47+11.06(1.3)^{c}$ \\
\hline Voruciclib & $(0.6)$ & $2.73+0.86(14.3)^{c}$ & $79.39+9.17(0.7)$ & $130.21+9.07(1.1)^{c}$ \\
\hline $\begin{array}{l}+5 \mu \mathrm{M} \\
\text { Verapamil }\end{array}$ & $\begin{array}{c}0.12+0.06 \\
(0.6)\end{array}$ & & & \\
\hline Cisplatin & $\begin{array}{c}1.78+0.56 \\
\text { (1) }\end{array}$ & & & \\
\hline$+1 \mu \mathrm{M}$ & $1.56+0.23$ & $1.89+0.41(1.06)$ & $1834.68+116.35(1)$ & \\
\hline Voruciclib & $(0.8)$ & $1.63+0.36(0.9)$ & $1768.05+98.70(0.9)$ & $1803.93+86.01(0.9)$ \\
\hline$+5 \mu \mathrm{M}$ & $1.39+0.18$ & $1.54+0.20(0.8)$ & $1693.67+106.31(0.9)$ & $1701.87+101.36(0.9)$ \\
\hline Voruciclib & & $2.18+0.71(1.2)$ & $1708.18+123.56(0.9)$ & $1882.48+124.17$ (1) \\
\hline$+5 \mu \mathrm{M}$ & $1.95+0.63$ & & & \\
\hline Verapamil & $(1.09)$ & & & \\
\hline
\end{tabular}


HEK293/pcDNA3.1 and NCI-H460 cells. FTC at $5 \mu \mathrm{M}$ was used a positive control inhibitor of ABCG2.

Effect of voruciclib on
cells overexpressing cells overessing $A B C C 1$ and $A B C C 10$

To further investigate the specificity of voruciclib, its reversal activity was tested in cells overexpressing $\mathrm{ABCC} 1$ and $\mathrm{ABCC} 10$. As shown in Table 4, voruciclib at 1 and $5 \mu \mathrm{M}$ did not significantly decrease the $\mathrm{IC}_{50}$ value of vincristine $(A B C C 1$ substrate) in ABCC1-overexpressing HEK293/ABCC1 cells. However, voruciclib treatment showed a partial decrease in $\mathrm{IC}_{50}$ value of paclitaxel (ABCC10 substrate) on ABCC10-overexpressing HEK293/ABCC10 cells, suggesting that voruciclib partially sensitizes ABCC10-overexpressing cells to its substrate drugs but has no effect on ABCC1-mediated MDR.

Effect of voruciclib on the intracellular accumulation of doxorubicin or mitoxantrone in ABCB1- or ABCG2- overexpressing cells

Intracellular accumulation of doxorubicin or mitoxantrone was assessed to understand the mechanism by which voruciclib attenuates ABCB1 or ABCG2mediated MDR. Based on their fluorescence intensity, doxorubicin or mitoxantrone were found to be accumulated in the cytoplasm and nuclei of SW620 or NCI-H460 cells (Fig. 2A and 2B). Contrastingly, much weaker fluorescence was observed in the resistant SW620/AD300 or NCI-H460/MX20 cells. Pretreatment with voruciclib at $5 \mu \mathrm{M}$ significantly increased the fluorescence intensity in resistant cells with little or no change in the parental cells. Similar results were obtained for $5 \mu \mathrm{M}$ of verapamil or FTC.
Table 3. The effect of Voruciclib on reversal of ABCG2-mediated MDR. ${ }^{\text {a }} \mathrm{IC}_{50}$ values are represented as mean $\pm \mathrm{SD}$ of at least three independent experiments $(n=3)$ performed in triplicate. ${ }^{b}$ FR: Resistance fold was calculated by dividing the $\mathrm{IC}_{50}$ values of substrates in the presence or absence of inhibitor by the $\mathrm{IC}_{50}$ of parental cells without inhibitor. ${ }^{c} \mathrm{P}<0.05$ versus the control group without reversal agent

\begin{tabular}{lcc}
\hline \multirow{2}{*}{ Treatment } & \multicolumn{2}{c}{$\mathrm{IC}_{50} \pm \mathrm{SD}^{\mathrm{a}}(\mu \mathrm{M})\left(\mathrm{FR}^{\mathrm{b}}\right)$} \\
& NCI-H460 & NCI-H460/MX20 \\
\hline Mitoxantrone & & \\
$\quad+1 \mu \mathrm{M}$ & $0.23 \pm 0.08(1)$ & $21.33 \pm 0.75(92.7)$ \\
Voruciclib & $0.20 \pm 0.04(0.8)$ & $12.49 \pm 0.45(54.3)^{\mathrm{c}}$ \\
$\quad+5 \mu \mathrm{M}$ & $0.15 \pm 0.05(0.6)$ & $2.18 \pm 0.24(9.4)^{\mathrm{c}}$ \\
Voruciclib & $0.14 \pm 0.06(0.6)$ & $1.68 \pm 0.17(7.3)^{\mathrm{c}}$ \\
$\quad+5 \mu \mathrm{M}$ FTC & & \\
SN-38 & & \\
$\quad+1 \mu \mathrm{M}$ & $0.29 \pm 0.02(1)$ & $29.40 \pm 1.69(101.3)$ \\
Voruciclib & $0.29 \pm 0.03(1)$ & $17.87 \pm 1.19(61.6)^{\mathrm{c}}$ \\
$\quad+5 \mu \mathrm{M}$ & $0.29 \pm 0.05(1)$ & $1.44 \pm 0.53(4.96)^{\mathrm{c}}$ \\
$\quad$ Voruciclib & $0.28 \pm 0.02(0.9)$ & $0.98 \pm 0.20(3.3)^{\mathrm{c}}$ \\
$\quad+5 \mu \mathrm{M}$ FTC & & \\
Cisplatin & & \\
$\quad+1 \mu \mathrm{M}$ & $13.84 \pm 1.7(1)$ & $15.74 \pm 0.97(1.1)$ \\
Voruciclib & $16.26 \pm 1.03(1.1)$ & $15.84 \pm 1.17(1.1)$ \\
$\quad+5 \mu \mathrm{M}$ & $19.42 \pm 1.69(1.4)$ & $15.11 \pm 1.16(1.1)$ \\
Voruciclib & $13.86 \pm 1.12(1)$ & $12.41 \pm 1.09(0.9)$ \\
$\quad+5 \mu \mathrm{M}$ FTC & & \\
\hline
\end{tabular}

Effect of voruciclib on the cellular accumulation of

[ $\left.{ }^{3} \mathrm{H}\right]$-paclitaxel or [ $\left.{ }^{3} \mathrm{H}\right]$-mitoxantrone in ABCB1- or ABCG2- overexpressing cells

In order to quantify the accumulation effects of voruciclib, the cellular accumulation of $\left[{ }^{3} \mathrm{H}\right]$-paclitaxel or $\left[{ }^{3} \mathrm{H}\right]$-mitoxantrone was determined. As shown in Fig. 2C the incubation of SW620/AD300 cells with 1 or $5 \mu \mathrm{M}$ voruciclib significantly increased the intracellular accumulation of $\left[{ }^{3} \mathrm{H}\right]$-paclitaxel in a concentration-dependent manner as compared to the parental SW620 cells. Verapamil (5 $\mu \mathrm{M})$ also significantly increased the accumulation of $\left[{ }^{3} \mathrm{H}\right]-$ paclitaxel. Similarly, voruciclib $(1$ or $5 \mu \mathrm{M})$ showed a significantly higher $\left[{ }^{3} \mathrm{H}\right]$-mitoxantrone

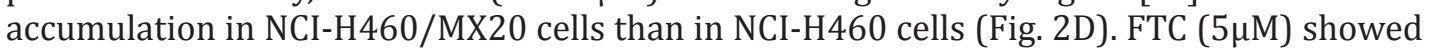
similar effect. 
Table 4. The effect of Voruciclib on reversal of ABCC1 and ABCC10-mediated MDR. ${ }^{a}$ IC $_{50}$ values are represented as mean $\pm S D$ of at least three independent experiments $(n=3)$ performed in triplicate. ${ }^{\mathrm{b}}$ FR: Resistance fold was calculated by dividing the $\mathrm{IC}_{50}$ values of substrates in the presence or absence of inhibitor by the $\mathrm{IC}_{50}$ of parental cells without inhibitor. ${ }^{\mathrm{c}} \mathrm{P}<0.05$ versus the control group without reversal agent

\begin{tabular}{|c|c|c|}
\hline \multirow[b]{2}{*}{ Treatment } & \multicolumn{2}{|c|}{$\mathrm{IC}_{50} \pm \mathrm{SD}^{\mathrm{a}}(\mathrm{nM}) \quad\left(\mathrm{FR}^{\mathrm{b}}\right)$} \\
\hline & HEK293/pcDNA3.1 & HEK293/ABCC1 \\
\hline \multicolumn{3}{|l|}{ Vincristine } \\
\hline$+1 \mu \mathrm{M}$ & $1.86 \pm 0.19(1)$ & $90.78 \pm 3.11(48.8)$ \\
\hline Voruciclib & $1.83 \pm 0.27(0.9)$ & $88.96 \pm 2.15(47.8)$ \\
\hline$+5 \mu \mathrm{M}$ & $1.82 \pm 0.23(0.9)$ & $84.07 \pm 2.54(45.1)$ \\
\hline Voruciclib & $1.83 \pm 0.35(0.9)$ & $9.98 \pm 0.86(5.3)^{c}$ \\
\hline & \multicolumn{2}{|c|}{$\mathrm{IC}_{50} \pm \mathrm{SD}^{\mathrm{a}} \quad(\mathrm{nM}) \quad\left(\mathrm{FR}^{\mathrm{b}}\right)$} \\
\hline Compounds & HEK293/pcDNA3.1 & HEK293/ABCC10 \\
\hline \multicolumn{3}{|l|}{ Paclitaxel } \\
\hline$+1 \mu \mathrm{M}$ & $0.94 \pm 0.02(1)$ & $23.3 \pm 0.96(24.7)$ \\
\hline Voruciclib & $0.98 \pm 0.03(1)$ & $17.41 \pm 0.38(18.5)$ \\
\hline $\begin{array}{r}+5 \mu \mathrm{M} \\
\end{array}$ & $0.99 \pm 0.08$ & $8.10 \pm 0.64(8.6)^{c}$ \\
\hline $\begin{array}{r}\text { Voruciclib } \\
+5 u M\end{array}$ & $0.96 \pm 0.02(1)$ & $0.88 \pm 0.04(0.9)^{c}$ \\
\hline Cepharathine & & \\
\hline
\end{tabular}

Fig. 2. Effect of voruciclib on the accumulation of the substrates of ABCB1 and ABCG2. Doxorubicin accumulation fluorescence in voruciclib $(5 \mu \mathrm{M})$ treated and untreated SW620 and SW620/ AD300 cells (A). Mitoxantrone accumulation fluorescence in voruciclib $(5 \mu \mathrm{M})$ treated and untreated NCI-H460 and NCIH460/MX20 cells (B). Scale bar, $10 \mu \mathrm{m}$. The effect of voruciclib on accumulation of $\left[{ }^{3} \mathrm{H}\right]$ paclitaxel in SW620 and SW620/AD300 cells (C) and effect of voruciclib on accumu-
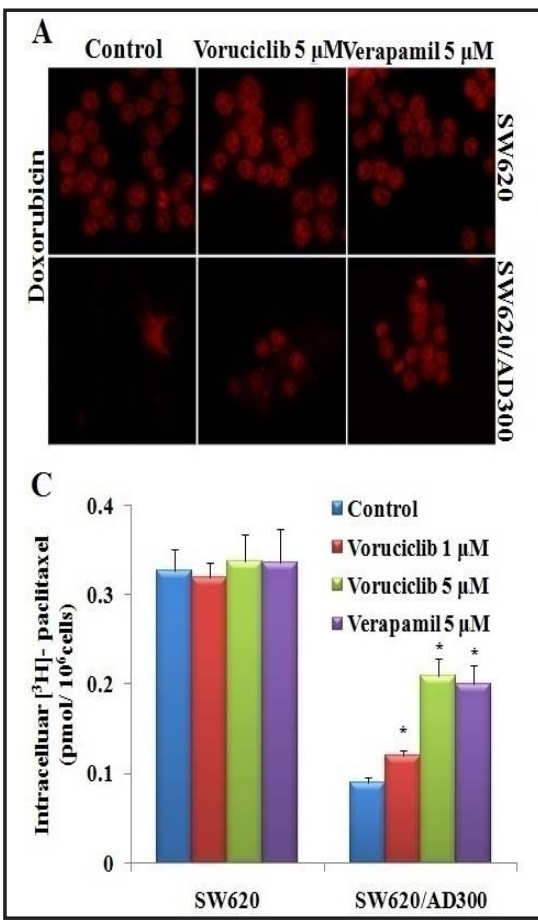
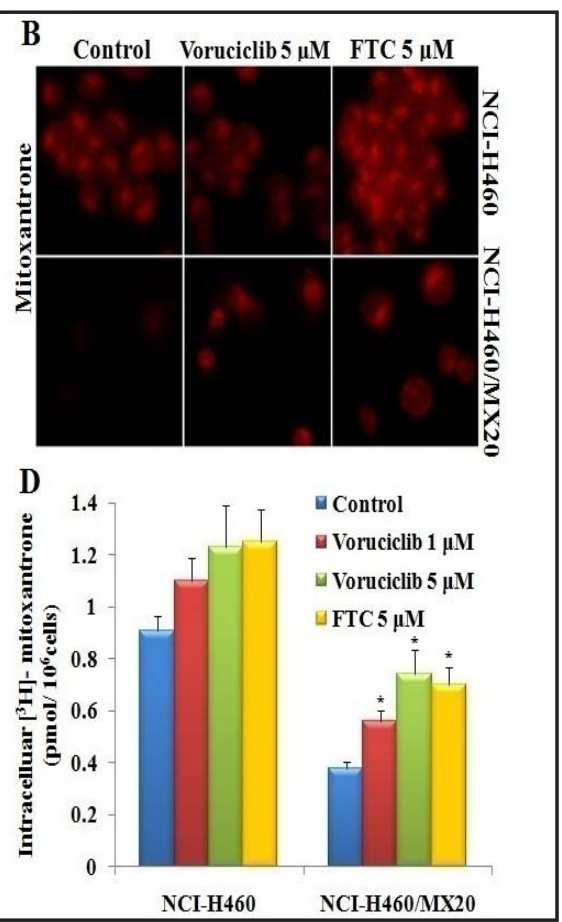

lation of $\left[{ }^{3} \mathrm{H}\right]$-mitoxantrone in NCI-H460 and NCI-H460/MX20 cells (D). Columns are the mean of triplicate determinations $(n=3)$, error bars represent the $S D$, and $* \mathrm{p}<0.05$ versus the control group. Verapamil $5 \mu \mathrm{M}$ or FTC $5 \mu \mathrm{M}$ is used as positive control for ABCB1- or ABCG2-overexpressing cells, respectively.

\section{Effect of voruciclib on the efflux of [ $\left.{ }^{3} \mathrm{H}\right]$-paclitaxel or $\left[{ }^{3} \mathrm{H}\right]$-mitoxantrone}

To ascertain that the increase in intracellular accumulation of $\left[{ }^{3} \mathrm{H}\right]$-paclitaxel or $\left[{ }^{3} \mathrm{H}\right]$ mitoxantrone was due to inhibition of ABCB1 or ABCG2 efflux function, we determined the efflux of $\left[{ }^{3} \mathrm{H}\right]$-paclitaxel or $\left[{ }^{3} \mathrm{H}\right]$-mitoxantrone from ABCB1- or ABCG2- overexpressing cells. As shown in Fig $3 \mathrm{~A}$ and $3 \mathrm{~B}$, in the absence of voruciclib, the remaining intracellular amount of $\left[{ }^{3} \mathrm{H}\right]$-paclitaxel in SW620/AD300 cells was significantly lower than that of SW620 cells, due to the efflux of $\left[{ }^{3} \mathrm{H}\right]$-paclitaxel by ABCB1. However, in the presence of voruciclib 1 or 5 $\mu \mathrm{M})$, the efflux of $\left[{ }^{3} \mathrm{H}\right]$-paclitaxel from SW620/AD300 cells significantly decreased in a timedependent manner. Furthermore, a similar reduction in efflux of $\left[{ }^{3} \mathrm{H}\right]$-mitoxantrone from NCI-H460/MX20 cells was observed after treatment with voruciclib at 1 or $5 \mu \mathrm{M}$ (Fig. 3C and $3 \mathrm{D})$. Moreover, these results were comparable to the decrease in efflux of $\left[{ }^{3} \mathrm{H}\right]$-paclitaxel or $\left[{ }^{3} \mathrm{H}\right]$-mitoxantrone by verapamil or FTC at $5 \mu \mathrm{M}$. 
Fig. 3. Effect of voruciclib on the efflux of the substrates of ABCB1 and ABCG2.A time course $(0,30,60,120$ min) versus percentage of intracellular $\left[{ }^{3} \mathrm{H}\right]$-paclitaxel remaining $(\%)$ was plotted to show effect of voruciclib in SW620 (A) and SW620/AD300 (B). A time course $(0,30,60$, $120 \mathrm{~min}$ ) versus percentage of intracellular $\left[{ }^{3} \mathrm{H}\right]$-mitoxantrone remaining (\%) was plotted to show effect of voruciclib in NCI-H460 (C) and NCI-H460/ MX20 (D) cells. Lines are the mean of tripli-
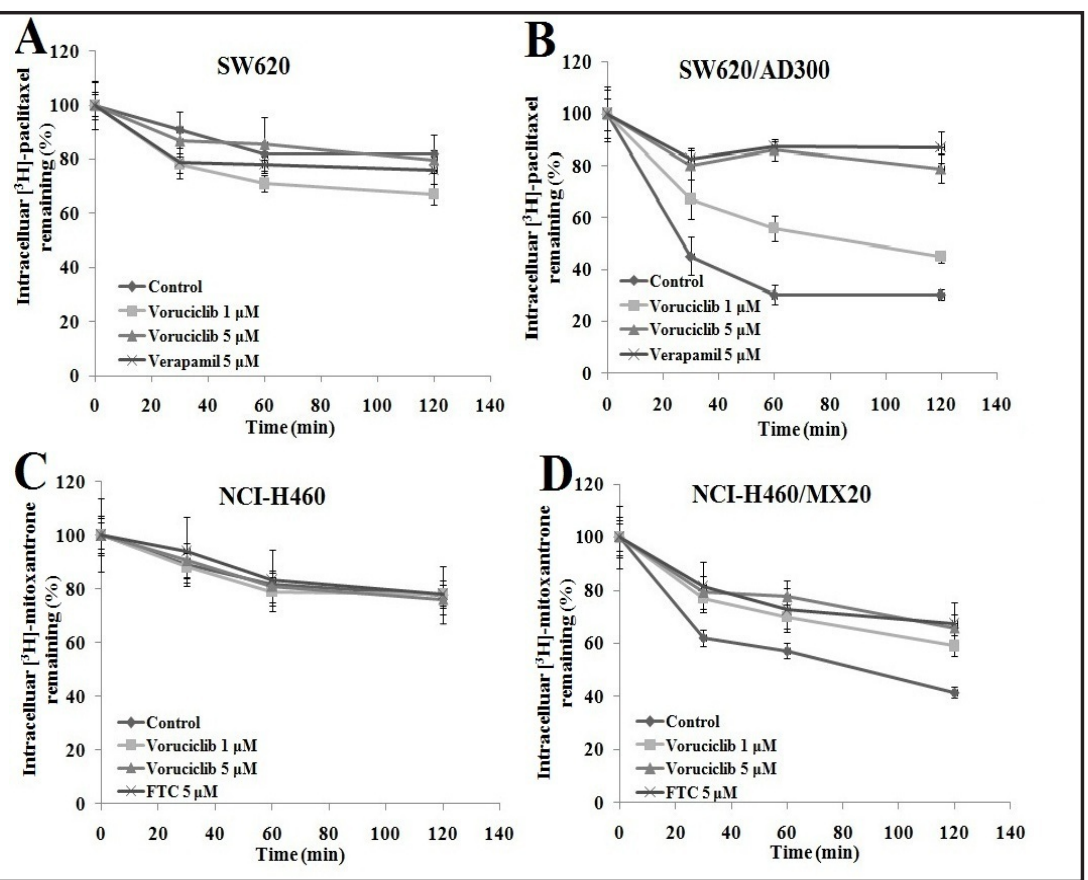
cate determinations $(n=3)$. Error bars represent the SD and ${ }^{*} \mathrm{p}<0.05$ versus the control group. Verapamil 5 $\mu \mathrm{M}$ or FTC $5 \mu \mathrm{M}$ is used as positive control for ABCB1- or ABCG2-overexpressing cells, respectively.

Fig. 4. Effect of voruciclib on the expression and sub-cellular localization of ABCB1 and ABCG2. The effect of voruciclib on the expression of $\mathrm{ABCB} 1$ and ABCG2 was tested after the cells were treated with $5 \mu \mathrm{M}$ voruciclib for $0,24,48,72$, and $96 \mathrm{~h}$ (A, C). Equal amounts of total cell lysates were used for each sample. Western blot analysis was performed and grayscale ratios of $\mathrm{ABCB} 1 / \beta$-actin and ABCG2 / $\beta$-actin were determined with Image J.

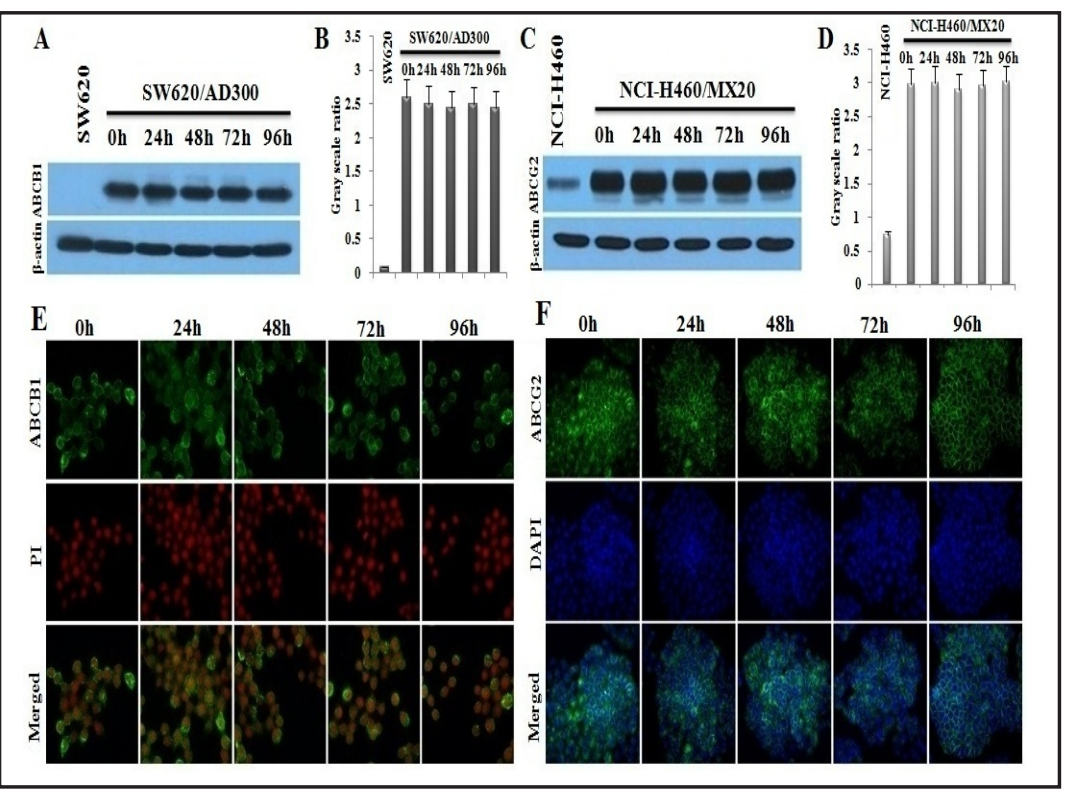
The grayscale ratios were proportional to the ABCB1 or ABCG2 protein levels (B, D). The differences were not statistically significant ( $p$ > 0.05).The effect of voruciclib at $5 \mu \mathrm{M}$ on the subcellular localization of ABCB1 or ABCG2 in ABCB1overexpressing SW620/AD300 (E) or ABCG2-overexpressing NCI-H460/MX20 cells (F) Scale bar, $10 \mu \mathrm{m}$. PI (propidium iodide, red) and DAPI (blue) counterstains the nuclei.

Effect of voruciclib on the expression and intracellular localization of ABCB1 or ABCG2

Western blot analysis was carried out to determine the effect of voruciclib on the expression of ABCB1 or ABCG2. There was no significant change in the protein expression 
Fig. 5. Effect of voruciclib on orthovanadate (Vi)-sensitive ABCB1 and ABCG2 ATPase activity. Crude membranes $(10 \mu \mathrm{g}$ protein/reaction) from High-five cells expressing ABCB1 or ABCG2 were incubated with increasing concentrations of voruciclib $(0-40 \mu \mathrm{M})$. Concentration of voruciclib was plotted at (A) linear and (B) log scale for ABCB1 or (C) linear and (D) log scale for ABCG2. The inset shows

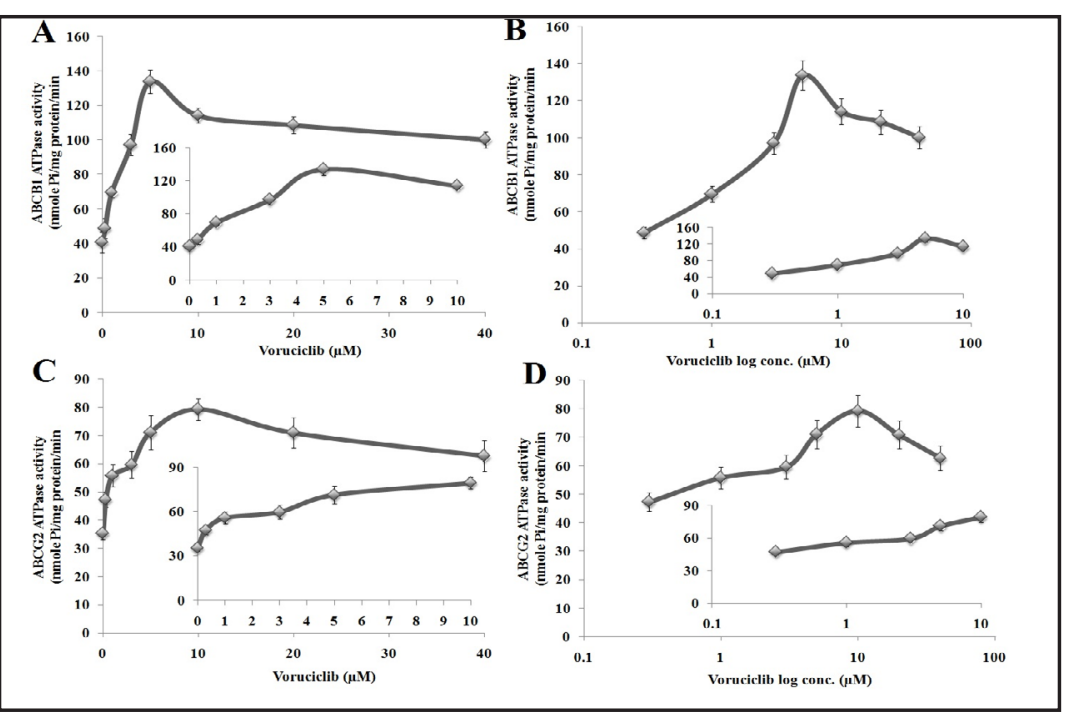
stimulation of ATP hydrolysis at concentration of $0-10 \mu$ Mvoruciclib. The mean values are plotted and error bars depict SD obtained from the average of atheist three independent experiments.

of ABCB1 or ABCG2 in SW620/AD300 (Fig. 4A and 4B) or NCI-H460/MX20 (Fig. 4C and 4D) cells, respectively upon voruciclib $(5 \mu \mathrm{M})$ treatment for $96 \mathrm{~h}$.

Although, Western blotting results confirmed that voruciclib does not alter the expression of $A B C B 1$ or $A B C G 2$, its effects on the translocation of ABCB1 or ABCG2 from plasma membrane to cytoplasm were uncertain. Immunofluorescence staining of the SW620/AD300 (Fig. 4E) and NCI-H460/MX20 (Fig. 4F) cells showed that voruciclib $(5 \mu \mathrm{M})$ did not significantly change the sub cellular distribution of ABCB1 or ABCG2.

\section{Effect of voruciclib on the ATPase activity of ABCB1 or ABCG2}

To assess the effect of voruciclib on the ATPase activity ofABCB1 or ABCG2, we measured ABCB1 or ABCG2-mediated ATP hydrolysis in the presence of voruciclib. Voruciclib stimulated the vanadate-sensitive ATPase activity of ABCB1 (Fig. 5A and 5B) or ABCG2 (Fig. $5 \mathrm{C}$ and 5D) in a concentration-dependent manner with a fold-stimulation of 3.2 or 2.2 -fold, respectively of the basal activity. The concentration of voruciclib required to obtain $50 \%$ of maximal stimulation is $0.72 \mu \mathrm{M}$ or $0.77 \mu \mathrm{M}$ for ABCB1 or ABCG2, respectively.

\section{Effect of voruciclib on apoptosis of ABCB1- or ABCG2- overexpressing cells}

Apoptosis assay was carried out to determine the percentage of apoptotic cells induced by indicated regimens. As shown in Fig. 6A and 6B, in the absence of paclitaxel, the apoptotic cell percentage in parental SW620 and ABCB1-overexpressing SW620/AD300 cells was not significantly affected by voruciclib $(5 \mu \mathrm{M})$ or verapamil $(5 \mu \mathrm{M})$. On treatment with paclitaxel $(50 \mathrm{nM})$, the percentage of apoptotic cells increased significantly from $1.9 \%$ to $28.5 \%$ in SW620 cells (Fig. 6A and 6C). However, paclitaxel (50 nM) did not significantly increase the percentage of apoptotic cells in SW620/AD300 cells (Fig. 6B and 6D). Interestingly, voruciclib or verapamil, at $5 \mu \mathrm{M}$, significantly increased the level of apoptosis induced by paclitaxel in SW620/AD300 cells from approximately $20 \%$ to $42.7 \%$ and $44 \%$, respectively.

Furthermore, in the absence of mitoxantrone, the percentage of apoptotic cells was similar and remains unaffected by voruciclib $(5 \mu \mathrm{M})$ or FTC $(5 \mu \mathrm{M})$ in parental NCI-H460 and NCI-H460/MX20 cells (Fig. 6E and 6F). Mitoxantrone (50 nM) increased the percentage of apoptotic cells from $6 \%$ to $19.3 \%$ in $\mathrm{H} 460$ cells (Fig. $6 \mathrm{G}$ ) while no significant change was observed in NCI-H460/MX20 cells (Fig. 6H). Moreover, voruciclib or FTC, at $5 \mu \mathrm{M}$, significantly increased the level of apoptosis induced by mitoxantrone in NCI-H460/MX20 cells from approximately $24.8 \%$ to $53.9 \%$ and $54.0 \%$, respectively. 
Fig. 6. Effect of voruciclib on paclitaxel or mitoxantrone-induced apoptosis in ABCB1- or ABCG2overexpressing cells. The parental SW620 and ABCB1-overexpressing SW620/AD300 cells were treated with voruciclib or verapamil, at $5 \mu \mathrm{M}$, alone $(\mathrm{A}, \mathrm{B})$ or in combination with paclitaxel $50 \mathrm{nM}$ (C, D). The parental NCIH460 or ABCG2-overexpressing NCI-H460/ MX20 cells were treated with voruciclib or FTC, at $5 \mu \mathrm{M}$, alone (E, F) or in combination with mitoxantrone $50 \mathrm{nM}(\mathrm{G}, \mathrm{H})$. The apoptotic cell population was quantified by flow cytometry. Bar graphs represent average cell population of three independent experiments and error bars represents SD.

Interaction analysis of vorucicilib-ABCB1 and voruciclib-ABCG2 induced-fit docked complexes The best scored pose of voruciclib exhibited a high docking score of $-11.419 \mathrm{kcal} /$ mol within the transmembrane domain of human homology ABCB1. As shown in Fig. 7A, the 2-chlor4-trifluormethyl phenyl ring was stabilized by nearby resi-
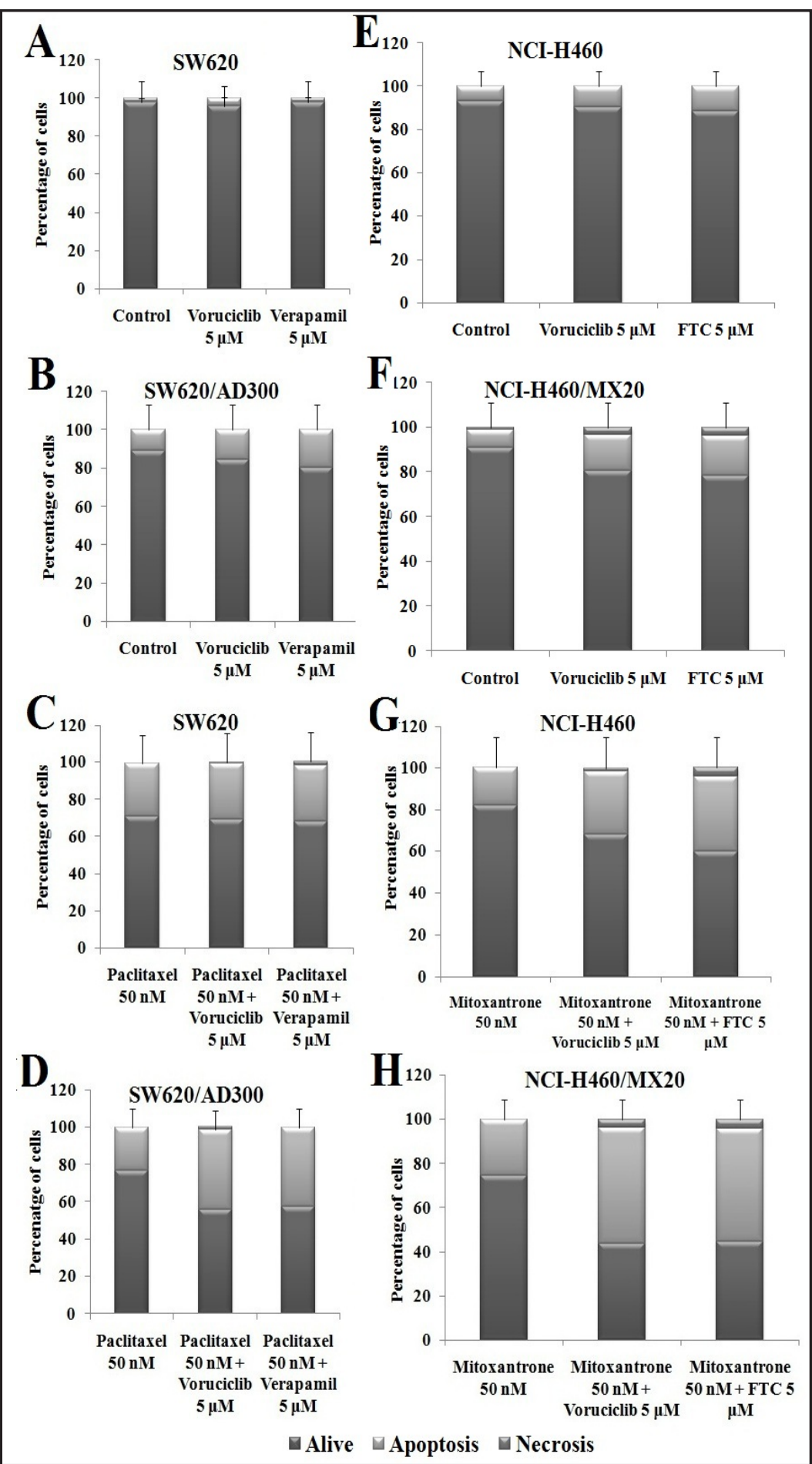
dues Met69, Phe336, Ile340, Ala729, Phe732 and Phe983 through hydrophobic interactions. Moreover, the side chain phenyl ring of residue Phe983 formed a $\pi-\pi$ stacking interaction with the phenyl ring of voruciclib. An intra-ligand hydrogen bond was formed in between 5 -hydroxyl and ketone group of 5, 7-dihydroxyl chromone ring of voruciclib (OH.. OC, $1.9 \AA$ ). The 5-hydroxyl group formed an electrostatic interaction with side chain amino group of $\mathrm{Gln} 990\left(\mathrm{HO} \cdot \cdot \mathrm{H}_{2} \mathrm{~N}-\mathrm{Gln} 990\right.$, $2.2 \AA$ ). The 7-hydroxyl group formed another electrostatic interaction with side chain hydroxyl group of Tyr307 (OH・. OH-Tyr307, $2.5 \AA \AA$ ). The 2-hydroxylmethyl group on the pyr- 
Fig. 7. Binding geometry of voruciclib into human homology ABCB1 and ABCG2 binding pocket by Glide IFD algorithms. (A) Interactions between voruciclib (carbon: yellow) and nearby residues (carbon: green) inside ABCB1. Dotted yellow line: hydrogen bonds. Dotted black line: electrostatic interactions. Dotted blue line: $\pi-\pi$ stacking interaction. Dotted green line: cation $-\pi$ interaction. (B) Interactions between voruciclib and nearby residue inside ABCG2. The color scheme is same as panel A except carbon atoms in ABCG2 are colored light blue.

rolidine ring of voruciclib formed a hydrogen bond with Gln725 $\left(\mathrm{CH}_{2}-\mathrm{OH} \cdot\right.$. OC-Gln725, $\left.2.2 \AA\right)$. The positively charged nitrogen atom of pyrrolidine ring formed three cation- $\pi$ interactions with nearby aromatic residues Tyr310, Phe728 and Phe759.

Similarly, voruciclib exhibited a docking score of $-10.304 \mathrm{kcal} /$ mol within the transmembrane

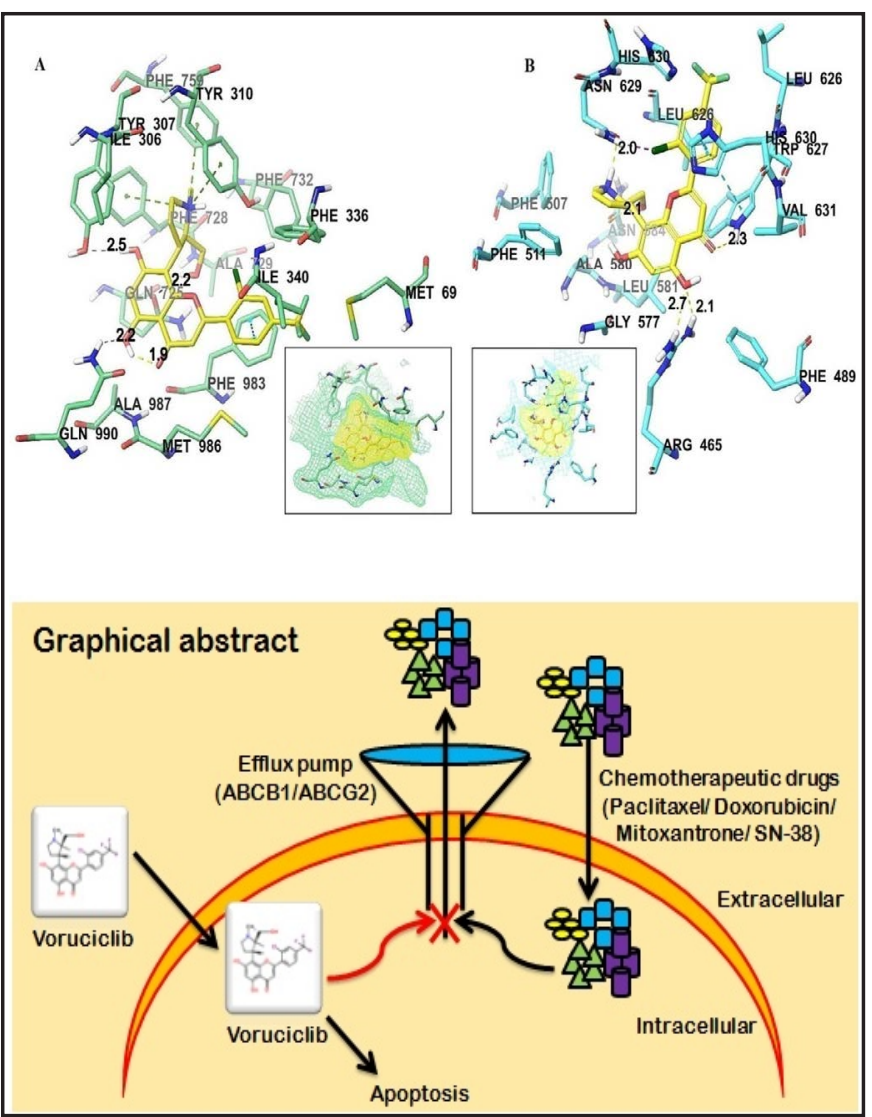
domain of human homology of ABCG2 (Fig.7B). Two $\pi-\pi$ stacking interactions were observed between the 2-chlor-4-trifluormethyl phenyl ring and the aromatic side chains of His 630 and Trp 627. Besides, multiple hydrogen interactions were formed between voruciclib and nearby residues. The 5-hydroxyl group of 5, 7-dihydroxyl chromone ring formed two hydrogen bonds with guanidine group of Arg $465\left(0 \cdot \cdot \mathrm{H}_{2} \mathrm{~N}-\mathrm{Arg} 465,2.7 \AA\right.$ and $2.1 \AA$ ). The positively charged pyrrolidine ring formed a hydrogen bond with side chain of Asn629 (NH.* OC-Asn629, 2.0 ). The 2-hydroxylmethyl group on the pyrrolidine ring of voruciclib formed another hydrogen bond with side chain of Asn584 (OH.. OC-Asn584, 2.0 Å). The ketone group of 5, 7-dihydroxyl chromone ring of voruciclib formed a hydrogen bond with side chain of Trp 627 (CO.* HN-Trp627, $2.3 \AA$ Å).

\section{Discussion}

The CDK targeting agents such as voruciclib, ribociclib, palbociclib, daniciclib, and abemaciclib have shown potent anti-cancer activity in metastatic breast cancer, myeloma, and neuroblastoma $[32,33]$. However, except abemaciclib none of these agents have been tested for their ability to overcome MDR in cancer cells [34].

One major finding of this study was that voruciclib $(1$ and $5 \mu \mathrm{M})$ significantly enhanced the sensitivity of ABCB1- or ABCG2- overexpressing cells to their respective substrate chemotherapeutic drugs. As evident from our MTT results, voruciclib produced a significant decrease in the $\mathrm{IC}_{50}$ values of paclitaxel and doxorubicin in ABCB1- overexpressing cells or mitoxantrone and SN-38 in ABCG2- overexpressing cells. Studies in the past have shown that mutation at position 482 in ABCG2 affects inhibitory activity such as that of novobiocin $[14,35,36]$. Convincingly, our results showed that voruciclib inhibits the activity of both wild-type (R482) and mutant (R482G and R482T) ABCG2. Furthermore, voruciclib (5 $\mu \mathrm{M})$ partially reversed ABCC10 but not ABCC1-mediated MDR.

\section{KARGER}




\section{Cellular Physiology Cell Physiol Biochem 2018;45:1515-1528

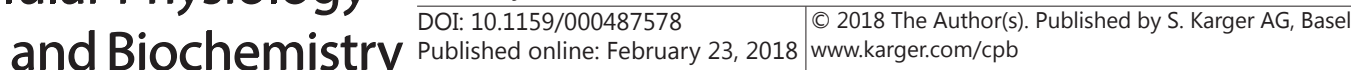 \\ Gupta et al.: Voruciclib Reverses ABCB1 and ABCG2 Mediated MDR}

In order to gain insight into the mechanism of action of voruciclib, we assessed the effect of voruciclib on i) cellular accumulation of doxorubicin and mitoxantrone, ii) [ $\left.{ }^{3} \mathrm{H}\right]-$ paclitaxel and $\left[{ }^{3} \mathrm{H}\right]$-mitoxantrone accumulation, and (iii) the efflux of $\left[{ }^{3} \mathrm{H}\right]$-paclitaxel and $\left[{ }^{3} \mathrm{H}\right]$-mitoxantrone from ABCB1- or ABCG2- overexpressing cells. In consistent with previous studies, voruciclib produced a concentration-dependent increase in response to substrate drugs in the resistant cells but not in parental cells $[37,38]$. It could be argued that the reversal activity of voruciclib may be due to the downregulation of ABCB1 or ABCG2. However, it is unlikely because our results showed that there was no alteration in the expression of ABCB1 or ABCG2 in cells upon treatment with voruciclib for $96 \mathrm{~h}$. Moreover, voruciclib did not translocate $\mathrm{ABCB} 1$ or ABCG2 from the cell membrane to cytoplasm or nucleus thus, indicating that the sensitizing effects of voruciclib on ABCB1- or ABCG2-overexpressing cells is directly related to its inhibition of function of these transporters.

It is well known that the energy required for the functioning of $A B C$ transporters is derived from the hydrolysis of ATP by the enzyme ATPase, and liberation of inorganic phosphate (pi) $[5,39,40]$. Our results indicated that voruciclib stimulated the ATPase activity of both $A B C B 1$ and $A B C G 2$, suggesting that it interacts with the drug-substrate-binding site and might competitively inhibit ABCB1 and ABCG2 activity [41-43]. Lastly, investigation of cell death revealed that voruciclib, at non-toxic concentration of $5 \mu \mathrm{M}$, potentiated paclitaxel or mitoxantrone-mediated apoptosis in drug resistant SW620/AD300 or NCI-H460/MX20 cells. Our findings were similar to Hsiao et al. that osimertinib, at non-toxic concentration, induces colchicine-mediated apoptosis in drug resistant KB-V-1 cells [44], suggesting the apoptotic effect of voruciclib in combination with substrate chemotherapeutic drugs.

Collectively, the results of this study indicated that voruciclib, at non-toxic concentrations, reverses $A B C B 1$ and $A B C G 2-m e d i a t e d$ MDR by directly inhibiting their efflux function. Combination of voruciclib with the substrates of ABCB1 and ABCG2 could be of great interest in clinical applications.

\section{Acknowledgements}

The authors are thankful to Drs. Susan E. Bates and Robert W. Robey (NIH, MD) for providing SW620, SW620/AD300, NCI-H460/MX20, and ABCG2-transfected cell lines, and FTC (ABCG2 inhibitor). We are thankful to Dr. Suresh Ambudkar (NIH, MD) for providing HEK293/pcDNA3.1 and HEK293/ABCC1 cells (NIH, MD), and Drs. Michael M. Gottesman and K.L. Fung for providing the LLC-PK1 and LLC-PK1/MDR1 cells. We would also like to thank Dr. Stephen Aller (The University of Alabama at Birmingham, Birmingham, AL) for providing human ABCB1 homology model and Drs. Mark F. Rosenberg (University of Manchester, Manchester, UK) and Zsolt Bikádi (Virtua Drug Ltd., Budapest, Hungary) for providing coordinates of ABCG2 homology model. We thank ChemieTek (Indianapolis, IN) for providing us free sample of Voruciclib.

Ms. Kimberly Lu from Great Neck South High School, New York and Mr. Richard Peng is a student from Stuyvesant High School, New York.

This work was supported by the National Institute of Health-USA (1R15GM116043-01), the St. John's University Research Seed Grant (No. 579-1110-7002), Natural Science Foundation of Guangdong (2016A030313029 and 2017A030313668), Sanming Project of Medicine in Shenzhen (SZSM201612031) and International Cooperation Foundation of Shenzhen (GJHZ20160301163138685).

This article does not contain any studies performed with human or animal participants.

\section{Disclosure Statement}

The authors declare no Disclosure Statement. 


\section{Cellular Physiology Cell Physiol Biochem 2018;45:1515-1528

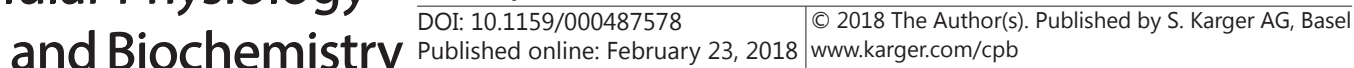

Gupta et al.: Voruciclib Reverses ABCB1 and ABCG2 Mediated MDR

\section{References}

1 Anreddy N, Gupta P, Kathawala RJ, Patel A, Wurpel JN, Chen ZS: Tyrosine kinase inhibitors as reversal agents for ABC transporter mediated drug resistance. Molecules 2014;19:13848-13877.

-2 Kathawala RJ, Gupta P, Ashby CR, Chen ZS: The modulation of ABC transporter-mediated multidrug resistance in cancer: a review of the past decade. Drug Resist Updat 2015;18:1-17.

3 Zhang YK, Wang YJ, Gupta P, Chen ZS: Multidrug Resistance Proteins (MRPs) and Cancer Therapy. AAPS J 2015;17:802-812.

4 Gupta P, Jani KA, Yang DH, Sadoqi M, Squillante E, Chen ZS: Revisiting the role of nanoparticles as modulators of drug resistance and metabolism in cancer. Expert Opin Drug Metab Toxicol 2016;12:281289.

5 Gottesman MM, Ambudkar SV: Overview: ABC transporters and human disease. J Bioenerg Biomembr 2001;33:453-458.

6 Gottesman MM, Fojo T, Bates SE: Multidrug resistance in cancer: role of ATP-dependent transporters. Nat Rev Cancer 2002;2:48-58.

7 Li W, Zhang H, Assaraf YG, Zhao K, Xu X, Xie J, Yang DH, Chen ZS: Overcoming ABC transporter-mediated multidrug resistance: Molecular mechanisms and novel therapeutic drug strategies. Drug Resist Updat 2016;27:14-29.

8 Gillet JP, Gottesman MM: Advances in the molecular detection of ABC transporters involved in multidrug resistance in cancer. Curr Pharm Biotechnol 2011;12:686-692.

-9 Shukla S, Chen ZS, Ambudkar SV: Tyrosine kinase inhibitors as modulators of ABC transporter-mediated drug resistance. Drug Resist Updat 2012;15:70-80.

10 Kim SW, Kwon HY, Chi DW, Shim JH, Park JD, Lee YH, Pyo S, Rhee DK: Reversal of P-glycoprotein-mediated multidrug resistance by ginsenoside $\operatorname{Rg}(3)$. Biochem Pharmacol 2003;65:75-82.

11 Ozvegy-Laczka C, Hegedus T, Várady G, Ujhelly O, Schuetz JD, Váradi A, Kéri G, Orfi L, Német K, Sarkadi B: High-affinity interaction of tyrosine kinase inhibitors with the ABCG2 multidrug transporter. Mol Pharmacol 2004;65:1485-1495.

12 Marchetti S, de Vries NA, Buckle T, Bolijn MJ, van Eijndhoven MA, Beijnen JH, Mazzanti R, van Tellingen O, Schellens JH: Effect of the ATP-binding cassette drug transporters ABCB1, ABCG2, and ABCC2 on erlotinib hydrochloride (Tarceva) disposition in in vitro and in vivo pharmacokinetic studies employing Bcrp1-/-/ Mdr1a/1b-/- (triple-knockout) and wild-type mice. Mol Cancer Ther 2008;7:2280-2287.

13 Lemos C, Jansen G, Peters GJ: Drug transporters: recent advances concerning BCRP and tyrosine kinase inhibitors. Br J Cancer 2008;98:857-862.

14 Mao Q Unadkat JD: Role of the breast cancer resistance protein (ABCG2) in drug transport. AAPS J 2005;7:E118-133.

15 Abraham I, El Sayed K, Chen ZS, Guo H: Current status on marine products with reversal effect on cancer multidrug resistance. Mar Drugs 2012;10:2312-2321.

16 Zhang Y, Zhang YK, Wang YJ, Vispute SG, Jain S, Chen Y, Li J, Youssef DT, El Sayed KA, Chen ZS: Esters of the marine-derived triterpene sipholenol A reverse P-GP-mediated drug resistance. Mar Drugs 2015;13:22672286.

17 Paiva C, Godbersen JC, Soderquist RS, Rowland T, Kilmarx S, Spurgeon SE, Brown JR, Srinivasa SP, Danilov AV: Cyclin-Dependent Kinase Inhibitor P1446A Induces Apoptosis in a JNK/p38 MAPK-Dependent Manner in Chronic Lymphocytic Leukemia B-Cells. PLoS One 2015;10:e0143685.

18 Eliades P, Miller DM, Miao B, Kumar R, Taylor M, Buch S, Srinivasa SP, Flaherty KT, Tsao H: A novel multiCDK inhibitor P1446A-05 restricts melanoma growth and produces synergistic effects in combination with MAPK pathway inhibitors. Cancer Biol Ther 2016;17:778-784.

19 Zhang YK, Zhang GN, Wang YJ, Patel BA, Talele TT, Yang DH, Chen ZS: Bafetinib (INNO-406) reverses multidrug resistance by inhibiting the efflux function of ABCB1 and ABCG2 transporters. Sci Rep 2016;6:25694.

20 Fung KL, Pan J, Ohnuma S, Lund PE, Pixley JN, Kimchi-Sarfaty C, Ambudkar SV, Gottesman MM: MDR1 synonymous polymorphisms alter transporter specificity and protein stability in a stable epithelial monolayer. Cancer Res 2014;74:598-608.

-21 Zhang H, Wang YJ, Zhang YK, Wang DS, Kathawala RJ, Patel A, Talele TT, Chen ZS, Fu LW: AST1306, a potent EGFR inhibitor, antagonizes ATP-binding cassette subfamily G member 2-mediated multidrug resistance. Cancer Lett 2014;350:61-68.

-22 Wang YJ, Zhang YK, Zhang GN, Al Rihani SB, Wei MN, Gupta P, Zhang XY, Shukla S, Ambudkar SV, Kaddoumi A, Shi Z, Chen ZS: Regorafenib overcomes chemotherapeutic multidrug resistance mediated by ABCB1 transporter in colorectal cancer: In vitro and in vivo study. Cancer Lett 2017;396:145-154. 


\section{Cellular Physiology Cell Physiol Biochem 2018;45:1515-1528 \begin{tabular}{l|l|l|l|}
\hline DOI: 10.1159/000487578 2018 The Author(s). Published by S. Karger AG, Basel & and Biochemistry \\
wublished onarger.com/cpb
\end{tabular}}

Gupta et al.: Voruciclib Reverses ABCB1 and ABCG2 Mediated MDR

23 Deng W, Dai CL, Chen JJ, Kathawala RJ, Sun YL, Chen HF, Fu LW, Chen ZS: Tandutinib (MLN518) reverses multidrug resistance by inhibiting the efflux activity of the multidrug resistance protein 7 (ABCC10). Oncol Rep 2013;29:2479-2485.

24 Gupta P, Xie M, Narayanan S, Wang YJ, Wang XQ, Yuan T, Wang Z, Yang DH, Chen ZS: GSK1904529A, a Potent IGF-IR Inhibitor, Reverses MRP1-mediated Multidrug Resistance. J Cell Biochem 2017;118:3260-3267.

25 Anreddy N, Patel A, Zhang YK, Wang YJ, Shukla S, Kathawala RJ, Kumar P, Gupta P, Ambudkar SV, Wurpel JN, Chen ZS, Guo H: A-803467, a tetrodotoxin-resistant sodium channel blocker, modulates ABCG2-mediated MDR in vitro and in vivo. Oncotarget 2015;6:39276-39291.

-26 Zhang XY, Zhang YK, Wang YJ, Gupta P, Zeng L, Xu M, Wang XQ, Yang DH, Chen ZS: Osimertinib (AZD9291), a Mutant-Selective EGFR Inhibitor, Reverses ABCB1-Mediated Drug Resistance in Cancer Cells. Molecules 2016;21. pii: E1236.

27 Ambudkar SV: Drug-stimulatable ATPase activity in crude membranes of human MDR1-transfected mammalian cells. Methods Enzymol 1998;292:504-514.

28 Gupta P, Kathawala RJ, Wei L, Wang F, Wang X, Druker BJ, Fu LW, Chen ZS: PBA2, a novel inhibitor of imatinib-resistant BCR-ABL T315I mutation in chronic myeloid leukemia. Cancer Lett 2016;383:220-229.

29 Holló Z, Homolya L, Davis CW, Sarkadi B: Calcein accumulation as a fluorometric functional assay of the multidrug transporter. Biochim Biophys Acta 1994;1191:384-388.

-30 Zhang YK, Zhang H, Zhang GN, Wang YJ, Kathawala RJ, Si R, Patel BA, Xu J, Chen ZS: Semi-synthetic ocotillol analogues as selective ABCB1-mediated drug resistance reversal agents. Oncotarget 2015;6:24277-24290.

-31 Zhang YK, Zhang XY, Zhang GN, Wang YJ, Xu H, Zhang D, Shukla S, Liu L, Yang DH, Ambudkar SV, Chen ZS: Selective reversal of BCRP-mediated MDR by VEGFR-2 inhibitor ZM323881. Biochem Pharmacol 2017;132:29-37.

32 O’Leary B, Finn RS, Turner NC: Treating cancer with selective CDK4/6 inhibitors. Nat Rev Clin Oncol 2016;13:417-430.

-33 Xu H, Yu S, Liu Q, Yuan X, Mani S, Pestell RG, Wu K: Recent advances of highly selective CDK4/6 inhibitors in breast cancer. J Hematol Oncol 2017;10:97.

-34 Wu T, Chen Z, To KK, Fang X, Wang F, Cheng B, Fu L: Effect of abemaciclib (LY2835219) on enhancement of chemotherapeutic agents in ABCB1 and ABCG2 overexpressing cells in vitro and in vivo. Biochem Pharmacol 2017;124:29-42.

-35 Natarajan K, Xie Y, Baer MR, Ross DD: Role of breast cancer resistance protein (BCRP/ABCG2) in cancer drug resistance. Biochem Pharmacol 2012;83:1084-1103.

-36 Robey RW, Honjo Y, Morisaki K, Nadjem TA, Runge S, Risbood M, Poruchynsky MS, Bates SE: Mutations at amino-acid 482 in the ABCG2 gene affect substrate and antagonist specificity. Br J Cancer 2003;89:19711978.

-37 Kathawala RJ, Chen JJ, Zhang YK, Wang YJ, Patel A, Wang DS, Talele TT, Ashby CR, Chen ZS: Masitinib antagonizes ATP-binding cassette subfamily G member 2-mediated multidrug resistance. Int J Oncol 2014;44:1634-1642.

-38 Shukla S, Robey RW, Bates SE, Ambudkar SV: Sunitinib (Sutent, SU11248), a small-molecule receptor tyrosine kinase inhibitor, blocks function of the ATP-binding cassette $(\mathrm{ABC}$ ) transporters P-glycoprotein (ABCB1) and ABCG2. Drug Metab Dispos 2009;37:359-365.

-39 Wilkens S: Structure and mechanism of ABC transporters. F1000Prime Rep 2015;7:14.

40 Rees DC, Johnson E, Lewinson O: ABC transporters: the power to change. Nat Rev Mol Cell Biol 2009;10:218-227.

41 Zhang H, Kathawala RJ, Wang YJ, Zhang YK, Patel A, Shukla S, Robey RW, Talele TT, Ashby CR, Ambudkar SV, Bates SE, Fu LW, Chen ZS: Linsitinib (OSI-906) antagonizes ATP-binding cassette subfamily G member 2 and subfamily C member 10-mediated drug resistance. Int J Biochem Cell Biol 2014;51:111-119.

42 Zhang H, Zhang YK, Wang YJ, Kathawala RJ, Patel A, Zhu H, Sodani K, Talele TT, Ambudkar SV, Chen ZS, Fu LW: WHI-P154 enhances the chemotherapeutic effect of anticancer agents in ABCG2-overexpressing cells. Cancer Sci 2014;105:1071-1078.

-43 Zheng LS, Wang F, Li YH, Zhang X, Chen LM, Liang YJ, Dai CL, Yan YY, Tao LY, Mi YJ, Yang AK, To KK, Fu LW: Vandetanib (Zactima, ZD6474) antagonizes ABCC1- and ABCG2-mediated multidrug resistance by inhibition of their transport function. PLoS One 2009;4:e5172.

44 Hsiao SH, Lu YJ, Li YQ Huang YH, Hsieh CH, Wu CP: Osimertinib (AZD9291) Attenuates the Function of Multidrug Resistance-Linked ATP-Binding Cassette Transporter ABCB1 in vitro. Mol Pharm 2016;13:21172125 . 